\title{
A Challenge for a Unique Dengue Vector Control Programme: Assessment of the Spatial Variation of Insecticide Resistance Status amongst Aedes aegypti and Aedes albopictus Populations in Gampaha District, Sri Lanka
}

\author{
Rasika Dalpadado ${ }^{(D)}{ }^{1}$ Nayana Gunathilaka $\left(\mathbb{D},{ }^{2}\right.$ Deepika Amarasinghe $\left(\mathbb{D},{ }^{3}\right.$ \\ and Lahiru Udayanaga ${ }^{4}{ }^{4}$ \\ ${ }^{1}$ Regional Director of Health Services Office, Gampaha District, Gampaha, Sri Lanka \\ ${ }^{2}$ Department of Parasitology, Faculty of Medicine, University of Kelaniya, Ragama, Sri Lanka \\ ${ }^{3}$ Department of Zoology and Environmental Management, Faculty of Science, University of Kelaniya, Dalugama, Sri Lanka \\ ${ }^{4}$ Department of Biosystems Engineering, Faculty of Agriculture and Plantation Management, Wayamba University of Sri Lanka, \\ Makadura, Sri Lanka
}

Correspondence should be addressed to Nayana Gunathilaka; n.gunathilaka@kln.ac.lk

Received 15 November 2020; Revised 11 March 2021; Accepted 24 March 2021; Published 5 April 2021

Academic Editor: Ettore Napoli

Copyright (c) 2021 Rasika Dalpadado et al. This is an open access article distributed under the Creative Commons Attribution License, which permits unrestricted use, distribution, and reproduction in any medium, provided the original work is properly cited.

Background. To date, dengue is considered an important public health problem in Sri Lanka. Irrational use of insecticides without evidence-based applications has primed the development of resistance in mosquito vectors. Method. The present study investigated the resistance status of Aedes aegypti and Aedes albopictus to commonly used insecticides in three selected Medical Officer of Health $(\mathrm{MOH})$ areas (i.e., Attanagalla, Dompe, and Negombo) in Gampaha District, Western Province of Sri Lanka. Entomological surveys were performed using ovitraps and larval collections. Larval bioassays were carried out to determine the $\mathrm{LC}_{50}, \mathrm{LC}_{90}$, and $\mathrm{LC}_{95}$ and susceptibility status for organophosphate temephos, whereas adult bioassays were performed to test the $0.03 \%$ deltamethrin and $0.8 \%$ malathion susceptibility. Results. The study revealed that the temephos concentrations required to control Ae. aegypti (13.7-17.7 times) and Ae. albopictus (4.6-7.6 times) are higher than the diagnostic concentration $(0.012 \mathrm{mg} / \mathrm{L})$ proposed by the World Health Organization. The highest resistance levels were observed for both Ae. aegypti (14 \pm 1.87$)$ and Ae. albopictus $(36 \pm 1.87)$ collected from the Negombo MOH area. Therefore, the WHO recommended diagnostic concentration is no longer effective in controlling Ae. aegypti and Ae. albopictus larvae in these areas. Both the dengue vectors have evolved a high level of insecticide resistance to malathion and deltamethrin in the Gampaha District except Ae. albopictus mosquitoes in rural areas. Further, vectors in rural areas are indicated susceptible $(>98 \%)$ to pyrethroids and emergence of resistance $(<97 \%)$ for organophosphate insecticides. Conclusion. The results of this study warrant the vector management authorities on the proper application of insecticides and rational use in vector control. The susceptibility status of vector mosquitoes should be continuously monitored especially in dengue-endemic areas parallel to the routine surveillance programme. Further molecular studies are strongly recommended to determine the Knockdown Resistance (kdr) mutations among Aedes populations.

\section{Background}

Dengue is the most rapidly spreading mosquito-borne viral disease in the world, affecting more than 2.5 million people in urban and periurban areas in over 100 countries, especially in South and Southeast Asia [1]. Aedes (Stegomyia) aegypti and Aedes (Stegomyia) albopictus are the two most important vectors of dengue in the world [2]. In the South-East Asian 
region, Ae aegypti is considered the principal epidemic vector of the dengue virus, while Ae. albopictus is an endemic vector, also contributing to the viral transmission [3].

In Sri Lanka, dengue was serologically diagnosed for the first time in 1960 and the first time as an allochthonous case in 1962 [4, 5]. Since early 2000, progressively larger epidemics of dengue with more cases of Dengue Hemorrhagic Fever (DHF) occurred at regular intervals. A major upward shift to a high incidence of dengue has been reported since 2009. For the last 5 years, approximately $47-55 \%$ of dengue cases have been reported in the Western Province of Sri Lanka and the second-highest number of dengue cases was reported from the Gampaha District [6] which is considered to be the most populated residential district in Sri Lanka.

Effective vaccines and therapies for most human diseases caused by arboviruses including dengue disease are still under a developmental stage [7]. Therefore, suppression of vector population and limiting the vector-human contact is the most reasonable way to control vector-borne diseases like dengue, because complete eradication of suitable vectors and elimination of pathogen or parasite is rather unrealistic through control approaches $[8,9]$.

Currently, vector control approaches are mainly based on source reduction, application of insecticides, public health education, and legislations [10-12]. The use of insecticides is considered the most efficient application in vector control programmes. Insecticide applications can thereby vary from aerosol-space spraying, coils, lotions, clothes, or curtains embedded with certain active insecticide compounds and mass fogging to the usage of larvicides in breeding waters [9]. Thermal fogs have been widely used for the control of Ae. aegypti and Ae. albopictus in Sri Lanka for several years especially during dengue outbreak situations [10].

The most commonly used insecticides in dengue control in Sri Lanka include technical malathion (organophosphate), Pesguard FG $161^{\circledR}$ (pyrethroids), temephos (organophosphates), and Bacillus thuringiensis israelensis (Bti-bio-pesticide). The technical malathion 95\% ULV and Pesguard FG 161 are used as adulticide and temephos 1\% SG, temephos $50 \mathrm{EC}$, and Bti use as larvicides in vector control [13]. Consequences of national policy interruption by the usage of massive insecticide-based controls with the same active compounds may cause developing resistance in vectors against the insecticides. Therefore, the use of insecticides to control mosquitoes should always be in line with insecticide resistance monitoring and management, which is a neglected component in vector control efforts.

Detailed evidence of insecticide resistance status of dengue vectors in Sri Lanka has been limitedly documented, and the effectiveness of some insecticides used for vector control is unknown. Investigations on the resistance status to the insecticides at the regional level are essential for effective chemical-based vector control interventions. The only documented study in the Gampaha District, Sri Lanka, has been conducted at a single location to represent the whole district. It has indicated that both Ae. aegypti and Ae. albopictus have evolved resistance to currently used insecticides in Sri Lanka $[10,14]$. However, such generalized data as evidence for vector control may not apply to the whole district. During the last five years, approximately $400 \mathrm{~kg}$ of technical malathion and $400 \mathrm{~L}$ of pyrethroid insecticides have been used each year for thermal fogging activities in the Negombo $\mathrm{MOH}$ area while usage of both organophosphates and pyrethroids was below $50 \mathrm{~kg}$ in rural $\mathrm{MOH}$ area like Dompe [15]. Therefore, the present study was conducted to provide the first descriptive figures to the insecticide resistance status of dengue vectors representing the urban, suburban, and rural populations in the district of Gampaha, Sri Lanka. This would facilitate in decision-making, implementing effective, economical, and sustainable dengue vector control measures in the district with the rational use of insecticides.

\section{Methods}

2.1. Study Area. The study was conducted in Gampaha District, in the Western Province of Sri Lanka, which records the second-highest number of dengue cases over the last two decades. It is being considered the highest residential population in Sri Lanka. The district extends over $1,387 \mathrm{~km}^{2}$ and has a population density of approximately 1,800. Three Medical Officer of Health $(\mathrm{MOH})$ areas, namely, Attanagalla $\left(7^{\circ} 05^{\prime} 60.00^{\prime \prime} \mathrm{N}\right.$ : $\left.80^{\circ} 06^{\prime} 60.00^{\prime \prime} \mathrm{E}\right)$, Dompe $\left(6^{\circ} 56^{\prime}\right.$ $25.42^{\prime \prime} \mathrm{N}$ : $\left.80^{\circ} 4^{\prime} 37.91^{\prime \prime} \mathrm{E}\right)$, and Negombo $\left(7^{\circ} 12^{\prime} 60.00^{\prime \prime} \mathrm{N}\right.$ : $79^{\circ} 49^{\prime} 59.99^{\prime \prime} \mathrm{E}$ ), were selected for the present study representing rural, suburban, and urban settings, respectively (Figure 1).

In the selection of study areas, geographic areas that are located inside towns and cities were described as urban whereas rural describe geographic areas that are located outside towns and cities, usually less developed with significant land cover under agriculture and/or natural vegetation. Areas with mixed characteristics were considered suburban [16].

2.2. Collection of Mosquitoes. Aedes eggs were collected from December 2016 to July 2019 at two-month intervals from all selected study sites using ovitraps. Ovitraps were prepared using black plastic cups of $250 \mathrm{~mL}$ capacity with filter papers as oviposition substrates. A total of 100 ovitraps was placed outdoor and indoor in randomly selected 50 houses in each locality. The positive ovitraps were collected after 5-7 days, and eggs were reared in the laboratory.

In each selected study area, larval and pupal collections were conducted every month by random sampling. A sentinel location was identified by selecting a house randomly each month. A minimum of 100 houses was surveyed within a radius of $200-300 \mathrm{~m}$ at the sentinel site selected. Larvae and pupae (F0 generation) were collected from permanent/temporary domestic and peridomestic breeding locations encountered in each selected area, separately. The live specimens were transferred into larval rearing vials and transported safely to the insectary at the Department of Parasitology, Faculty of Medicine, University of Kelaniya, Ragama, Sri Lanka.

2.3. Establishment of Adult Mosquito Colony. The immature stages collected from three study areas were reared at separate rearing cages under confined laboratory conditions $\left(27 \pm 2^{\circ} \mathrm{C} ; 75 \pm 5 \%\right.$ relative humidity $(\mathrm{RH}) ; 12: 12[\mathrm{~L}: \mathrm{D}] \mathrm{h}$ 


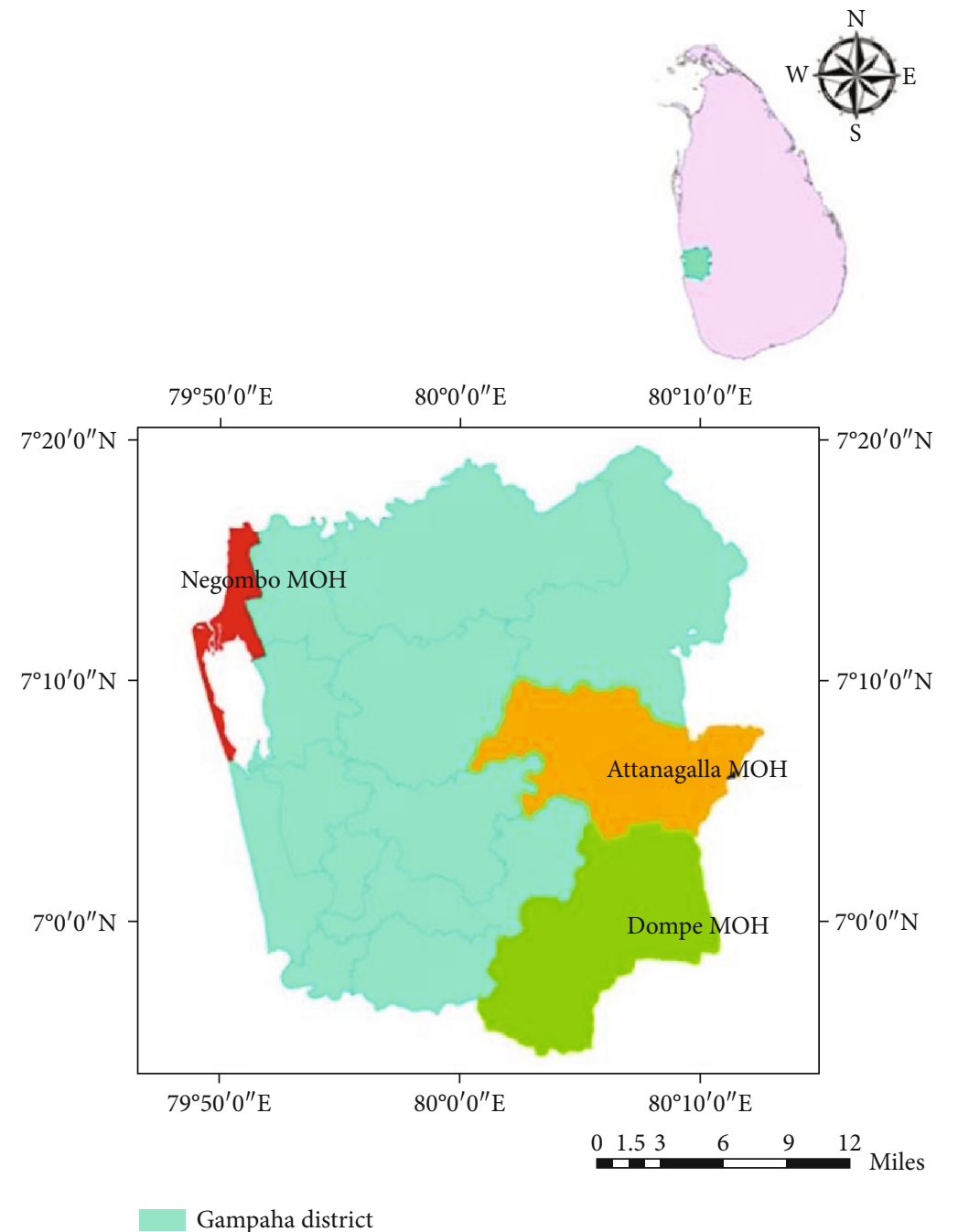

FIgURE 1: Location of the study areas in the Gampaha District, Sri Lanka.

photoperiod) with the recognition of the site collected. The larvae were fed with a specified larval diet formula described before $[17,18]$. Emerged mosquitoes were identified to the species level and reared separately at different cages according to the place of origin (urban, semiurban, or rural). The adult female mosquitoes were housed at mosquito rearing cages $\left(24 \times 24 \times 24 \mathrm{~cm}^{3}\right)$ with mesh screening on top, provided with a $10 \%$ sugar solution and water ad libitum twice a day (morning and evening).

2.4. Larval Susceptibility Test. Larval bioassays were conducted using WHO standard susceptibility test kits provided by the National Dengue Control Unit following the WHO protocol [12] to determine the efficacy of temephos (organophosphate). Concentrations of test solutions $(0.00625 \mathrm{mg} / \mathrm{L}$, $0.0125 \mathrm{mg} / \mathrm{L}, 0.025 \mathrm{mg} / \mathrm{L}, 0.0375 \mathrm{mg} / \mathrm{L}$, and $0.05 \mathrm{mg} / \mathrm{L}$ ) were prepared using $3.125 \mathrm{mg} / \mathrm{L}$ of temephos stock solution.

A batch of 20 field-collected larvae (III and IV instar stages) was introduced to each freshly prepared test solution series separately. The larval mortality was recorded after 24 hours of insecticide exposure. Larval bioassays for each concentration were repeated five times with control trials using the mosquitoes collected from each $\mathrm{MOH}$ separately to determine lethal concentrations (LC) which result in 50\%, $90 \%$, and $99 \%$ mortality $\left(\mathrm{LC}_{50}, \mathrm{LC}_{90}\right.$, and $\left.\mathrm{LC}_{99}\right)$. Water temperature was maintained $\left(25^{\circ} \mathrm{C} \pm 2^{\circ} \mathrm{C}\right)$ throughout the investigation. Moribund larvae were also added to dead larvae for calculating percentage mortality, and pupated larvae were discarded during the test. The tests were conducted separately for Ae. aegypti and Ae. albopictus collected from each selected study area.

2.5. Adult Susceptibility Assay. Three- to five-day-old female adult mosquitoes of Ae. aegypti and Ae. albopictus were selected for the adult bioassays according to the site of collection separately. The susceptibility was performed following standard guidelines of the WHO with tarsal contact exposure to the impregnated papers with insecticides in the standard kit [12]. Susceptibility level to $0.03 \%$ deltamethrin and $0.8 \%$ malathion was evaluated. A batch of 20 mosquitoes was exposed to the insecticide-treated paper line around the bioassay chamber, and the number of knock-down mosquitoes was recorded after the one-hour exposure period. 
The surviving mosquitoes were transferred to the holding tubes and fed with $5 \%$ sucrose solution. Mortality was enumerated after 24 hours of exposure, and the mortality rate was calculated. The experiment was repeated five times for each chemical and mosquito species collected from different locations with a control group on each occasion. If mosquito mortality in the control was exceeded $10 \%$, the corrected mortality was calculated using Abbott's formula [19]. The tests were rejected if the corrected mortality in the control exceeded $10 \%$.

2.6. Data Analysis and Interpretation. The mortality levels were defined as susceptible ( $>97 \%$ mortality), the emergence of possible resistance (90-97\% mortality), and resistant ( $<90 \%$ mortality) according to the susceptibility criteria defined by the WHO guidelines for Monitoring and managing insecticide resistance in Aedes mosquito populations [12]. When calculating larval mortality, test results were discarded if more than $10 \%$ of larvae pupated, while the control mortality was maintained between $5 \%$ and $20 \%$. In all the cases, corrected percentage mortality was calculated using Abbott's formula [19]. Similarly, during adult bioassays when adult mosquito mortality in the control tubes exceeded $>5 \%$ but less than $10 \%$, corrected mortalities were calculated for all treated groups using Abbott's formula [19].

Significance in the spatial variations in corrected percentage mortality of Aedes aegypti and Aedes albopictus larvae and adults was evaluated using the General Linear Model (GLM) followed by Tukey's test for mean separation. Probit analysis (combined with log transformation) was used to determine the susceptibility status of Aedes aegypti and Aedes albopictus larvae to temephos in three studied areas. SPSS (version 23) was used for data analysis.

\section{Results}

3.1. Insecticide Susceptibility of Aedes Larvae. The highest percentage mortalities for Ae. aegypti larvae were observed at the highest temephos concentration $(0.10 \mathrm{ppm})$ in Attanagalla $(99.0+2.7 \%)$ and Negombo $(95.0+2.7 \%)$, $\mathrm{MOH}$ areas. The lowest mortalities were recorded at $0.125 \mathrm{ppm}$ concentration of temephos in the same localities (Table 1). According to the GLM, the percentage mortality rates of Ae. aegypti larvae denoted a significantly increasing trend along with the temephos concentration in both Attanagalla $\left(F_{1,4}=195.05\right.$, $P<0.001)$ and Negombo $\left(F_{1,4}=155.22, P<0.001\right) \mathrm{MOH}$ areas at $95 \%$ level of confidence. Further, Ae. aegypti larvae from the Attanagalla $\mathrm{MOH}$ area were significantly more susceptible to temephos than Ae. aegypti larvae of Negombo at all the concentrations $\left(F_{1,8}=9.532, P<0.0001\right)$.

In $A$ e. albopictus, a gradual increase in percentage mortality was observed along with temephos concentration (Table 2). This trend was also found to be significant in all study areas $\left(F_{1,4}>44.91, P<0.001\right)$. Further, statistics of GLM evidenced that the percentage mortality rates of $A e$. albopictus larvae exposed to temephos varied significantly, among the three $\mathrm{MOH}$ areas $\left(F_{2,12}=15.73, P<0.001\right)$. The highest susceptibility of Ae. albopictus larvae was observed in Attanagalla $\mathrm{MOH}$ area, which reported the $99.0+1.0 \%$
(98.0-100.0\%) mortality at $0.375 \mathrm{ppm}$ concentration of temephos. In both Dompe and Negombo, the highest percentage mortality rates were observed as $99.0+1.0 \%$ at 0.05 ppm (Table 2).

3.2. Determination of 24-Hour $L_{50}$ and $L C_{99}$ for Exposed Aedes Larvae. The estimated $\mathrm{LC}_{50}$ and $\mathrm{LC}_{99}$ values of Ae. aegypti and Ae. albopictus larvae (24-hour exposure period) against temephos from the three $\mathrm{MOH}$ areas, along with 95\% Confidence Intervals (CI) retrieved from the Probit analysis, are indicated in Table 3 . The lowest $\mathrm{LC}_{50}$ (0.020 ppm [0.018-0.023]) and $\mathrm{LC}_{99}$ (0.171 ppm [0.1340.232]) values for Ae. aegypti larvae against temephos were observed from Attanagalla $\mathrm{MOH}$ area. In both Attanagalla and Negombo $\mathrm{MOH}$ areas, the $\mathrm{LC}_{99}$ values of Ae. aegypti for 24-hour exposure of temephos were 13.7 and 17.7 times higher than the WHO recommended concentration $(0.0125 \mathrm{ppm})$ for $99 \%$ eradication of Ae. aegypti larvae, respectively.

In Ae. albopictus larvae, the Dompe $\mathrm{MOH}$ area reported the lowest $\mathrm{LC}_{50}\left(0.008 \mathrm{ppm}\right.$ [0.006-0.010]) and $\mathrm{LC}_{99}$ (0.095 ppm [0.065-0.1710]) values. Similar to Ae. aegypti larvae, the $\mathrm{LC}_{99}$ values for 24-hour exposure of temephos were $>4.6$ times higher than the WHO recommended concentration $(0.0125 \mathrm{ppm})$ for $99 \%$ eradication of Ae. albopictus larvae (Table 3 ).

3.3. Insecticide Susceptibility of Adult Ae. aegypti and Ae. albopictus Mosquitoes. The percentage mortality rates of Ae. aegypti and Ae. albopictus adult mosquitoes exposed to deltamethrin and malathion are depicted in Figure 2. The highest mortality rates of Ae. aegypti exposed to deltamethrin and malathion were observed in Attanagalla as $91.4+6.2 \%$ and $81.2+3.1 \%$, respectively. Interestingly, only $53.1+8.2 \%$ of Ae. aegypti adults from Negombo were eradicated by malathion, denoting a relatively higher resistance (Figure 2). According to GLM, only percentage mortality rates of Ae. aegypti mosquitoes exposed to malathion denoted significant spatial variations $\left(F_{1,8}=77.78, P<0.001\right)$.

The percentage mortality of Ae. albopictus mosquitoes exposed to deltamethrin for 24 hours varied significantly $\left(F_{2,12}=11.76, P=0.01\right)$ at $95 \%$ level of confidence. Ae. albopictus mosquitoes from the Dompe $\mathrm{MOH}$ area denoted the highest percentage mortality against deltamethrin $(0.03 \%)$ as $97.8+3.0 \%$, while the lowest was observed from Negombo as $83.8+6.6 \%$ (Figure 2 ). A similar spatial variation was witnessed among Ae. albopictus mosquitoes exposed to malathion $(0.8 \%)$, which also remained to be significant $\left(F_{2,12}=27.40, P<0.0001\right)$. In this case, the highest mortality was observed from Dompe as $98.9+2.4 \%$, while Negombo reported the lowest as $70.8+6.2 \%$.

\section{Discussion}

Dengue vector control strategies largely depend upon the use of larvicides in the breeding sites to target the vectors at the immature stages in their life cycle and space sprays aiming at the adult infective stages of the potential dengue vectors [20]. The development of insecticide resistance is a major 
TABle 1: Percentage mortality rates of Ae. aegypti larvae exposed to different concentrations of temephos.

\begin{tabular}{lrr}
\hline Concentration/ppm & Attanagalla & Percentage mortality (\%) \\
\hline 0.125 & $36.0+1.9(34.1-37.9)$ & $14.0+1.8(12.2-15.8)$ \\
0.250 & $51.0+4.5(46.5-55.5)$ & $21.0+2.4(18.6-23.4)$ \\
0.375 & $64.0+1.9(62.1-65.9)$ & $36.0+1.9(34.1-37.9)$ \\
0.050 & $89.0+1.9(87.1-90.9)$ & $70.0+4.2(65.8-74.2)$ \\
0.100 & $99.0+1.7(97.3-100.0)$ & $95.0+2.7(92.3-97.7)$ \\
\hline
\end{tabular}

TABle 2: Percentage mortality rates of Ae. albopictus larvae exposed to different concentrations of temephos.

\begin{tabular}{lccr}
\hline Concentration $(\mathrm{ppm})$ & Attanagalla & Percentage mortality (\%) & Nompe \\
\hline 0.0625 & $45.0+2.7(42.3-47.7)$ & $49.0+3.6(45.4-52.6)$ & $10.0+4.2(5.8-14.2)$ \\
0.0125 & $78.0+2.5(75.5-79.5)$ & $58.0+3.0(55.0-61.0)$ & $50.0+2.2(47.8-52.2)$ \\
0.250 & $85.0+2.7(82.3-87.7)$ & $68.0+2.5(65.5-70.5)$ & $64.0+1.9(62.1-65.9)$ \\
0.375 & $99.0+1.0(98.0-100.0)$ & $80.0+3.5(76.5-83.5)$ & $85.0+1.6(83.4-86.6)$ \\
0.05 & $100.0+0.0$ & $99.0+1.0(98.0-100.0)$ & $99.0+1.0(98.0-100.0)$ \\
\hline
\end{tabular}

TABLE 3: $\mathrm{LC}_{50}$ and $\mathrm{LC}_{99}$ values of Ae. aegypti and Ae. albopictus larvae exposed to 24 hours for temephos.

\begin{tabular}{lcccc}
\hline Species & Study area & $\mathrm{LC}_{50}(\mathrm{ppm})$ & $\mathrm{LC}_{99}(\mathrm{ppm})$ & Resistance factor \\
\hline \multirow{2}{*}{ Aedes aegypti } & Negombo & $0.0381(0.036-0.042)$ & $0.221(0.181-0.280)$ & 17.7 \\
& Attanagalla & $0.020(0.018-0.023)$ & $0.171(0.134-0.232)$ & 13.7 \\
Aedes albopictus & Negombo & $0.015(0.014-0.017)$ & $0.088(0.073-0.110)$ & 7.0 \\
& Attanagalla & $0.007(0.006-0.008)$ & $0.058(0.046-0.076)$ & 4.6 \\
\end{tabular}

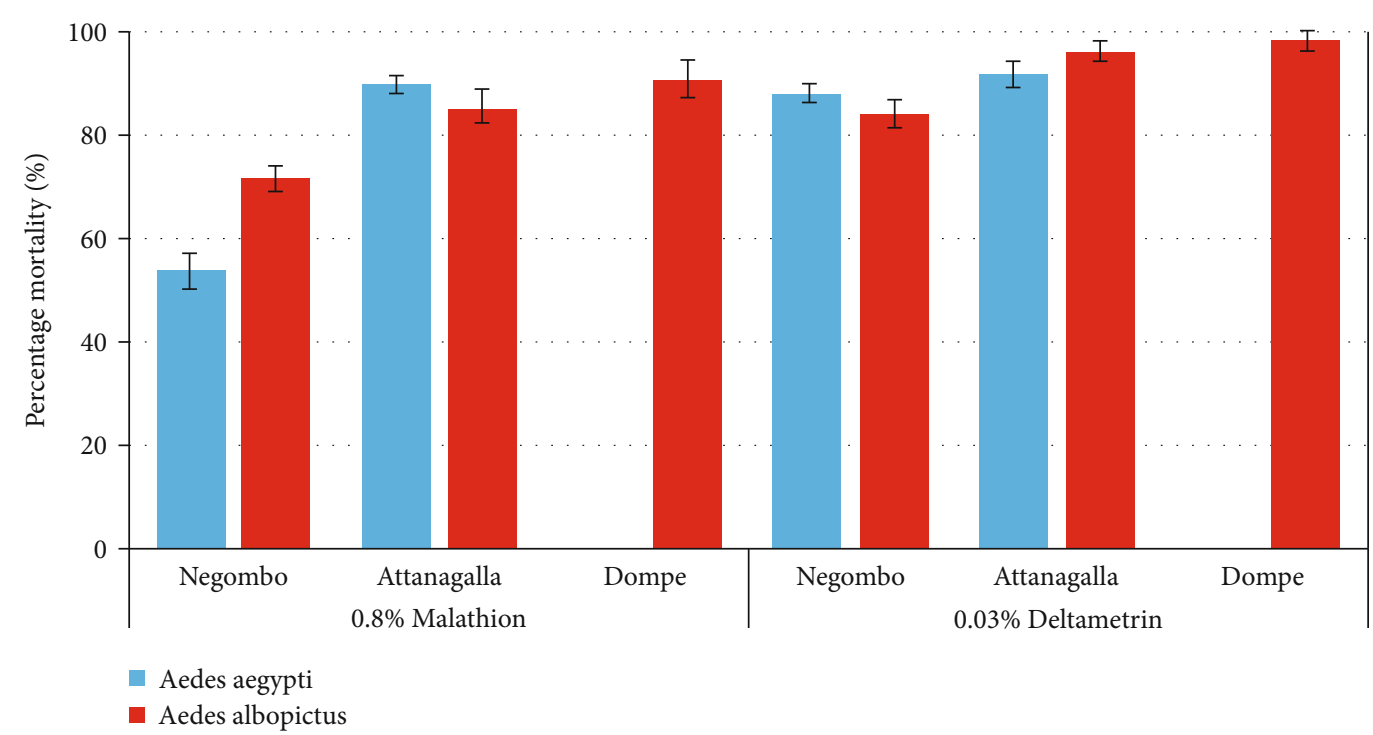

Figure 2: Percentage mortality rates of Ae. aegypti and Ae. albopictus females exposed to deltamethrin (0.03\%) and malathion (0.8\%) in the studied $\mathrm{MOH}$ areas.

threat to public health vector control measures all around the globe [21], including Sri Lanka [10, 14, 22]. However, there are limited published data on insecticide susceptibility. Spatial heterogeneity of insecticide resistance could have important implications for vector control efficacy, particularly when vector control strategies are designed to be applied across a large geographical area. The development of scientifically sound vector control and insecticide resistance management strategies for dengue vectors depends on the patterns and drivers of spatial heterogeneity in insecticide 
resistance [23]. The present study revealed the development of resistance to commonly used larvicide and adulticides among both the Ae. aegypti and Ae. albopictus population in Gampaha District, Sri Lanka.

According to the recommendation of the WHO, temephos $1 \%$ sand granules and temephos 50\% EC are the most suitable and approved larvicides for container breeders worldwide $[24,25]$. In Sri Lanka, temephos $1 \%$ sand granules are mainly recommended for Aedes control in domestic water storage containers that cannot be destroyed and covered with a lid and temephos 50\% EC promotes for large scale breeding grounds such as abandoned boats, concrete slabs, construction sites, and yards with machinery parts especially during dengue epidemics [13]. The efficacy of the larviciding effect of temephos is mainly dependent on the frequency of application, contact period, application dosage, and frequency of usage. However, it is noteworthy that the overuse of chemicals at higher doses facilitates the mosquito-resistant onset [26].

The present study indicated a higher prevalence of temephos resistance among both Ae. aegypti and Ae. albopictus in line with previous studies done in Sri Lanka and other countries. [24, 26-29]. The larval mortality rates for temephos were ranged from 14 to $36 \%$ for Ae. aegypti and 50-78\% for Ae. albopictus for the WHO discriminating dosage during the study. Based on the larval bioassay results, the highest temephos resistance for Ae. aegypti was observed from urban areas in Negombo which contributed to the highest number of dengue cases reported in the Gampaha District during the last five years [6]. This result was not that surprising due to the widespread and frequent application of insecticides for larval control activities in the area. Therefore, it could be stated that frequent applications of insecticide in urbanized areas have induced the resistance in Aedes population [24]. However, the continuous application of temephos in these areas may create untoward effects in the current vector control programmes. Hence, the application of the temephos chemical for vector control should be rotated with another alternative chemical group to delay the resistance development by the mosquitoes against the temephos.

A low level of resistance was observed in Ae. albopictus compare to Ae. aegypti especially in rural and suburban areas in Gampaha District in line with the previous studies [24, 30]. It can be stated that past efforts to control malaria epidemics may have contributed to the development of resistance among Aedes populations in rural settings. Chemical larviciding with temephos was first introduced in Sri Lanka as a supplementary malaria control measure in 1997, and still, it is continued to be used from time to time for malaria outbreak control activities within the country simultaneous with dengue [31]. In addition to the usage of chemicals in health programmes, the agriculture sector also utilizes a vast array of chemicals in which the usage in the health sector could be negligible. The $\mathrm{LC}_{99}$ for Ae. albopictus was highest in the Dompe $\mathrm{MOH}$ area which represents a rural setup.

In Sri Lanka, the Gampaha district has an ideal climatic and ecological environment for the cultivation of pineapple. Therefore, pineapple plantation is being continued commercially targeting both the local and foreign markets [32].
Therefore, agricultural use of organophosphate insecticides in pineapple plantations could be a reason for this higher level of resistance for temephos in this region. Hence, the present study warrants the need for a common regulating body for insecticide management integrating both public health and agricultural pest control activities and also to improve the knowledge of public health staff on integrated vector management including source reduction and biological vector control strategies.

In Sri Lanka, mostly, thermal fogging is conducted with pyrethroid insecticides, especially pesguard FG161 and occasionally with technical malathion on a rotational basis for the control of adult vector densities [13]. Recent studies have demonstrated either development of resistance or a decrease in the susceptibility to synthetic insecticides in Aedes mosquitoes in many counties in the world $[28,33,34]$. The present study also revealed the presence of resistance among $A e$. aegypti populations for both currently used organophosphate and pyrethroid insecticides in the Gampaha District, Sri Lanka.

Malathion resistance has been widely reported in both Ae. aegypti and Ae. albopictus mosquitoes in Sri Lanka [10, $14,24]$. The results of the current study also suggest that technical malathion has low efficacy in controlling both Ae. aegypti and Ae. albopictus mosquitoes especially in urban and suburban areas, where it has demonstrated a high level of resistance to the insecticide. The resistance to malathion might have been developed over time due to prolonged and frequent use in public health programmes during disease outbreaks situations [35]. The present study also indicates an emerging resistance to malathion in the Dompe area as the mortality obtained was below $97 \%$ for Ae. albopictus mosquitoes. Similarly, adult bioassay results of deltamethrin showed that tested mosquito species have also developed resistance to pyrethroid insecticides in the Gampaha District which is also associated with the extensive and routine application of pyrethroid in dengue control activities and increasing household use of pyrethroids.

This study found that in all three localities, Ae. aegypti were more resistant than Ae. albopictus for both pyrethroid and organophosphate insecticides. The high prevalence of resistance in Aedes aegypti could be due to high selective pressure with the frequent application and higher exposure to insecticide either during fogging by the health and local authorities. Since Ae. aegypti is an endophilic mosquito that prefers to rest and breed indoors [36], it is more likely to be exposed to household insecticides than Ae. albopictus. The emergence of a high level of resistance to both the currently used insecticide categories may create difficulty in determining suitable insecticides for dengue control and challenges in future vector control approaches. Most importantly, the development of resistance among Ae. albopictus population against pyrethroids insecticides is a major threat within the region since it is the predominant dengue vector in most of the suburban and rural areas of the country and pyrethroids are the most popular insecticide class all around the globe including Sri Lanka [14, 37].

The results of this study warrant the vector management authorities on the proper application of insecticides and 
rational use in vector control. Therefore, the susceptibility status of vector mosquitoes should be continuously monitored especially in dengue-endemic areas parallel to the routine surveillance programme. Therefore, the application of chemicals in public health vector control programmes should be carefully evaluated, and the insecticide resistance management system should be implemented with the collaboration of the entire vertical vector campaigns.

The study also indicates the importance of a molecular approach to determine the emergence and occurrence of Knockdown Resistance (kdr) mutations among Aedes populations due to the widespread use of pyrethroid chemicals to implement a successful insecticide resistance management programme in the country.

\section{Conclusion}

Variation in the resistance levels to the insecticides by the dengue vectors in different areas would be a challenging task for routine insecticide-based vector control approaches. Therefore, it should be allied with the susceptibility levels to insecticides by mosquito vectors. Further, the rational use of insecticides for vector control is a high priority. The present study warrants a common regulating body for insecticide management in conjunction with public health and agricultural pest control activities.

\section{Abbreviations}

EC: Emulsifiable concentrate

GLM: General Linear Model

Kdr: Knockdown Resistance

LC: Lethal concentration

MOH: Medical Officer of Health

WHO: World Health Organization.

\section{Data Availability}

All data are available from the authors and will be provided upon reasonable request.

\section{Conflicts of Interest}

The authors declare that they have no conflicts of interest regarding the content of this manuscript.

\section{Authors' Contributions}

$\mathrm{RD}$ is responsible for conducting field surveys, bioassays, and writing of the manuscript. NG is assigned to the design of the research, overall supervision of the research work, and writing of the manuscript. DA supervised the research work and reviewed the manuscript. LU assisted the statistical analysis. All authors read and approved the final manuscript.

\section{Acknowledgments}

We would like to extend our gratitude to the Provincial Director of Health Services, Western Province, and Deputy Regional Director of Health Services, Gampaha, Sri Lanka, for the support provided to conduct this study. All staff at the Entomology Unit Gampaha are acknowledged for facilitating field surveys and laboratory investigations. Head and Technical Staff at the Department of Parasitology, Faculty of Medicine, University of Kelaniya, Sri Lanka, are also acknowledged for the support extended to conduct larval and adult bioassays at the insectary established under the National Research Council Funded Project NRC 16-142. We would like to acknowledge National Dengue Control Unit, Sri Lanka, for providing Standard solutions to carry out larval bioassays.

\section{References}

[1] World Health Organization (WHO), "Comprehensive Guideline for prevention and control of dengue and dengue hemorrhagic fever: Revised and expanded edition," 2011, 2020, https://apps.who.int/iris/handle/10665/204894.

[2] P. D. N. N. Sirisena and F. Noordeen, "Dengue control in Sri Lanka - improvements to the existing state of the art in the island," Sri Lankan Journal of Infectious Diseases, vol. 6, no. 1, pp. 2-16, 2016.

[3] L. Lambrechts, T. W. Scott, and D. J. Gubler, "Consequences of the expanding global distribution of Aedes albopictus for dengue virus transmission," PLoS Neglected Tropical Diseases, vol. 4, no. 5, article e646, 2010.

[4] P. D. N. N. Sirisena and F. Noordeen, "Evolution of dengue in Sri Lanka-changes in the virus, vector and climate," International Journal of Infectious Diseases, vol. 19, pp. 6-12, 2013.

[5] H. Tissera, N. Pannila-Hetti, P. Samaraweera, J. Weeraman, P. Palihawadana, and A. Amarasinghe, "Sustainable dengue prevention and control through a comprehensive integrated approach: the Sri Lankan perspective," WHO South-East Asia Journal of Public Health, vol. 5, no. 2, pp. 106-112, 2016.

[6] Epidemiology Unit Dengue update, Ministry of Health, Sri Lanka, 2018, 2020, http://www.epid.gov.lk/web/index .php?Itemid $=448 \% 23$.

[7] S. Swaminathan and N. Khanna, "Dengue vaccine development: global and Indian scenarios," International Journal of Infectious Diseases, vol. 84, pp. 80-86, 2019.

[8] A. C. Morrison, E. Z. Gutierrez, T. W. Scott, and R. Rosenberg, "Defining challenges and proposing solutions for control of the virus vector Aedes aegypti," PLoS Medicine, vol. 5, no. 3, article e68, 2008.

[9] P. H. Hamid, V. I. Ninditya, J. Prastowo, A. Haryanto, A. Taubert, and C. Hermosilla, "Current status of Aedes aegypti insecticide resistance development from Banjarmasin, Kalimantan, Indonesia," BioMed Research International, vol. 2018, Article ID 1735358, 7 pages, 2018.

[10] S. H. P. P. Karunaratne, T. C. Weeraratne, M. D. B. Perera, and S. N. Surendran, "Insecticide resistance and efficacy of space spraying and Larviciding in the control of dengue vectors Aedes aegypti and Aedes albopictus in Sri Lanka," Pesticide Biochemistry and Physiology, vol. 107, no. 1, pp. 98-105, 2013.

[11] World Health Organization (WHO), "Guidelines for diagnosis, treatment, prevention and control of dengue," 2009, 2020, https://www.who.int/tdr/publications/documents/ dengue-diagnosis.pdf.

[12] World Health Organization (WHO), "Monitoring and managing insecticide resistance in Aedes mosquito populations; 
Interim guidance for entomologists," 2016, 2020, https://apps .who.int/iris/handle/10665/204588.

[13] N. D. C. Unit, "Sri Lanka. Guidelines for Aedes Vector Surveillance and Control," 2016, 2018, http://www.dengue.health.gov .lk/web/phocadownload/guidlines_for_aedes_vector_ surveillance_and_control_in_sri_lanka_new.pdf.

[14] S. D. Fernando, M. Hapugoda, R. Perera, K. Saavedra-Rodriguez, W. C. Black, and N. K. De Silva, "First report of V1016G and S989P knockdown resistant (Kdr) mutations in pyrethroid-resistant Sri Lankan Aedes aegypti mosquitoes," Parasites \& Vectors, vol. 11, no. 1, p. 526, 2018.

[15] Epidemiology Unit, Regional Director of Health services office Gampaha, Personal Communication, Sri Lanka, 2019.

[16] B. A. Ndenga, F. M. Mutuku, H. N. Ngugi et al., "Characteristics of Aedes aegypti adult mosquitoes in rural and urban areas of western and coastal Kenya," PLoS One, vol. 12, no. 12, article e0189971, 2017.

[17] A. Puggioli, M. Carrieri, M. L. Dindo et al., "Development of Aedes albopictus (Diptera: Culicidae) larvae under different laboratory conditions," Journal of Medical Entomology, vol. 54, no. 1, pp. 142-149, 2017.

[18] P. A. D. H. N. Gunathilaka, U. M. H. U. Uduwawala, N. W. B. A. L. Udayanga, R. M. T. B. Ranathunge, L. D. Amarasinghe, and W. Abeyewickreme, "Determination of the efficiency of diets for larval development in mass rearing Aedes aegypti (Diptera: Culicidae)," Bulletin of Entomological Research, vol. 108, no. 5, pp. 583-592, 2018.

[19] W. S. Abbott, "A method of computing the effectiveness of an insecticide," Journal of Economic Entomology, vol. 18, no. 2, pp. 265-267, 1925.

[20] K. Yadav, B. Rabha, S. Dhiman, and V. Veer, "Multi-insecticide susceptibility evaluation of dengue vectors Stegomyia albopicta and St. aegypti in Assam, India," Parasites \& Vectors, vol. 8, no. 1, p. 143, 2015.

[21] M. Auteri, F. La Russa, V. Blanda, and A. Torina, "Insecticide resistance associated with $\mathrm{kdr}$ mutations in Aedes albopictus: an update on worldwide evidences," BioMed Research International, vol. 2018, Article ID 3098575, 10 pages, 2018.

[22] S. Dharshini, M. Vinobaba, P. J. Jude, S. H. P. P. Karunaratne, and S. N. Surendran, "Prevalence and insecticide susceptibility of dengue vectors in the district of Batticaloa in eastern Sri Lanka," Tropical Medicine and Health, vol. 39, no. 2, pp. 4752, 2011.

[23] R. Deming, P. Manrique-Saide, A. M. Barreiro et al., "Spatial variation of insecticide resistance in the dengue vector Aedes aegypti presents unique vector control challenges," Parasite \& Vectors, vol. 9, no. 1, p. 67, 2016.

[24] S. Fernando and N. D. Silva, "Insecticide susceptibility of Aedes albopictus from Sri Lanka: first report of the F1534C mutation in the country," Journal of Entomology and Zoological Studies, vol. 7, pp. 525-530, 2019.

[25] WHO, "Expert Committee on Vector Biology and Control \& World Health Organization, Safe use of pesticides: ninth report of the WHO Expert Committee on Vector Biology and Control," in meeting held in Geneva from 11 to 18 September 1984, World Health Organization, 1985, 2018, https://apps .who.int/iris/handle/10665/40165.

[26] A. Rahayu, U. Saraswati, E. Supriyati et al., "Prevalence and distribution of dengue virus in Aedes aegypti in Yogyakarta City before deployment of Wolbachia infected Aedes aegypti,"
International Journal of Environmental Research and Public Health, vol. 16, no. 10, p. 1742, 2019.

[27] N. Grisales, R. Poupardin, S. Gomez, I. Fonseca-Gonzalez, H. Ranson, and A. Lenhart, "Temephos resistance in Aedes aegypti in Colombia compromises dengue vector control," PLoS Neglected Tropical Diseases, vol. 7, no. 9, article e2438, 2013.

[28] B. Kamgang, S. Marcombe, F. Chandre et al., "Insecticide susceptibility of Aedes aegypti and Aedes albopictus in Central Africa," Parasites \& Vectors, vol. 4, no. 1, p. 79, 2011.

[29] R. Singh, P. Mittal, G. Kumar, and R. Dhiman, "Insecticide susceptibility status of Aedes aegypti and Anopheles stephensi larvae against temephos in Delhi, India," International Journal of Mosquito Research, vol. 1, no. 3, pp. 69-73, 2014.

[30] A. Ponlawat, J. G. Scott, and L. C. Harrington, "Insecticide susceptibility of Aedes aegypti and Aedes albopictus across Thailand," Journal of Medical Entomology, vol. 42, no. 5, pp. 821825, 2005.

[31] World Health Organization and Global Malaria Programme, "Eliminating Malaria. Case Study 3, Progress towards Elimination in Sri Lanka," 2012, 2018, https://www.who.int/malaria/ publications/atoz/9789241504454/en/.

[32] D. H. Piyumi and H. K. G. I. S. B. Hapuhinna, "Present situation and prospects of pineapple cultivation in Gampaha District," in Proceedings of 19th International Postgraduate Research conference (IPRC), Faculty of Graduate Studies, University of Kelaniya, p. 145, Sri Lanka, 2018.

[33] I. Dusfour, V. Thalmensy, P. Gaborit, J. Issaly, R. Carinci, and R. Girod, "Multiple insecticide resistance in Aedes aegypti (Diptera: Culicidae) populations compromises the effectiveness of dengue vector control in French Guiana," Memórias do Instituto Oswaldo Cruz, vol. 106, no. 3, pp. 346-352, 2011.

[34] H. A. A. Khan, W. Akram, K. Shehzad, and E. A. Shaalan, "First report of field evolved resistance to agrochemicals in dengue mosquito, Aedes albopictus (Diptera: Culicidae), from Pakistan," Parasites \& Vectors, vol. 4, no. 1, p. 146, 2011.

[35] S. H. P. P. Karunaratne, T. C. Weeraratne, M. D. B. Perera, and S. N. Surendran, "Insecticide resistance and, efficacy of space spraying and larviciding in the control of dengue vectors Aedes aegypti and Aedes albopictus in Sri Lanka," Pesticide Biochemistry and Physiology, vol. 107, no. 1, pp. 98-105, 2013.

[36] F. Dzul-Manzanilla, J. Ibarra-López, and W. B. Marín, "Indoor resting behavior of Aedes aegypti (Diptera: Culicidae) in Acapulco, Mexico," Journal of Medical Entomology, vol. 54, no. 2, pp. 501-504, 2016.

[37] L. P. Brito, J. G. B. Linss, T. N. Lima-Camara et al., “Assessing the effects of Aedes aegypti kdr mutations on pyrethroid resistance and its fitness cost," PLoS One, vol. 8, no. 4, article e60878, 2013. 